\title{
Formation of geometrical structure of manipulator for mechanized bridge
}

\author{
F. Kuczmarski, J. Zelkowski, M. Gontarczyk
}

\begin{abstract}
The Army use bridges to cross narrow water and terrain obstacles. The bridges are carried on wheel or caterpillar vehicles then they are laid on obstacle. Generally the bridges are not put by crane, but by special manipulator - called manipulator of mechanized bridge. This manipulator structure depends on kind of bridge and way of its laying.

Independently from constructional solutions, manipulator has large angles of turn of elements (over $180^{\circ}$ ) and transfer considerable burdens in initial and final stage of laying process. Moreover dimension and mass restrictions for whole mechanized bridge cause that manipulator ought to be compact and light construction.
\end{abstract}

In paper authors propose methodology of selection of geometrical structure for this type of devices. To accelerate process of searching right structures and geometrical parameters then to enlarge credibility of getting positive results, methods of structural synthesis were chosen. Authors emphasize importance of contemporary solutions in this area which enable preparing of preliminary foundations and requirements.

Authors introduce practical implementation of results on example of Polish new military bridge. Proposed methodology of creation of kinematic structure of mechanized bridges manipulator can be applied to other similar technical devices.

Index Terms - kinematic structure, manipulator, mechanized bridges

\section{INTRODUCTION}

New conditions and factors, which are expected in contemporary warfare area demand for present and next generation of combat vehicles adaptation to performance in various kinds of environment. Most important role in new combat systems plays maneuverability. One of elements

This work was supported by the Polish Ministry of Scientific Research and Information Technology under Grant nr 0 T00B 0224.

F. Kuczmarski is Director of Institute of Logistics, Command and Support Systems, Military University of Technology, 00-908 Warsaw, Kaliskiego 2 Street, Poland (phone: 4822-6839085; fax: 4822-6837382; e-mail: f.kuczmarski@wme.wat.edu.pl).

J. Zelkowski is from Institute of Logistics, Command and Support Systems, Military University of Technology, Warsaw (e-mail: jzelkowski@wat.edu.pl).

M. Gontarczyk is from Institute of Logistics, Command and Support Systems, Military University of Technology, Warsaw (e-mail: mgontarczyk@wat.edu.pl). maneuverability assurance system are equipment used in crossing water and terrain obstacles, particularly mechanized bridges. They ought to have similar levels of mobility than the vehicles they are intended to support.

Both Poland and many other countries lack mechanized bridge which fulfill contemporary requirements - so R\&D works related new construction of wheeled mechanized bridge were started. It will be scissors bridge which will have bridge span about $25 \mathrm{~m}$ length and load capacity class MLC 70 (MLC 110 for wheeled vehicles) - according to STANAG 2021 [12]. Presumed variant of new bridge takes into consideration current developmental tendencies in this kind of construction and is supposed to be competitive in comparison with present solutions.

\section{CHARACTERISTICS OF BRIDGE-LAYERS MANIPULATORS}

There are three basics elements in every contemporary mechanized bridge independently from its kind:

- $\quad$ bridge span - assuring to cross of field obstacles by vehicles;

- carrier (base vehicle) - enable moving of whole system in terrain and is source of energy for executing elements;

- $\quad$ bridge-layers manipulator-working mechanism enable arrangement and removal of bridge span.

Mechanized bridges according to way of arrangement of bridge span on obstacle, are divided into: ramp, pushed and spread (vertical swing, underslung, scissors, horizontal sliding, "gate-like"). In every solution bridge-layers manipulator differs ones construction thus play different role resulting from pattern of working cycle. The most simple solution of bridgelayers manipulator are implemented in pushed bridges as longitudinal guide beam. Spread bridges have the most complex and sophisticated bridge-layers manipulators from constructional point of view. Normally there are complex flat mechanisms composed of rotary or sliding kinematics pairs (simple and multiple) with moving link - hydraulic cylinder.

Analysis of contemporary solutions and newly initiated concepts and prototypes of mechanized bridges results that there are preferred two systems: scissors and horizontal sliding (fig. 1). Characteristics of performance of bridge-layers manipulator results from specifics of pattern of working cycle in mentioned above systems. In scissors construction bridge- 
layers manipulator - is main mechanism of lying. At first both semi-spans of the bridge are risen by mean of manipulator to vertical position then are moved past the vertical. While the bridge unfolds the bridge-layers manipulator continues its rotation until the bridge is full unfolded in the horizontal position then the span is laid on the opposite bank by its further rotation. In horizontal sliding bridges process of lying is performed in following way: the lower half of the bridge slides forward until its end is lined up with the end of the upper half then the two sections are locked together and extend over the gap. The bridge span is lowered into position and the cantilever arm withdrawn.

\section{DESIGN OF BRIDGE-LAYERS MANIPULATORS}

Performed analysis of accessible literature shows that process of design is spacious question and it cannot be strictly defined. From those reasons problem of design of working mechanism was taken by several authors ( e.g. $[1,2,6,11])$ in different aspect, and moreover there is lack of unified and strict methodology in design of such kind of systems. On the other hand review of literatures relate to reasonable process of making decision in engineering design clearly shows that in this process significant role plays utilization of procedures of mathematical programming by mean of well-known computer programs.

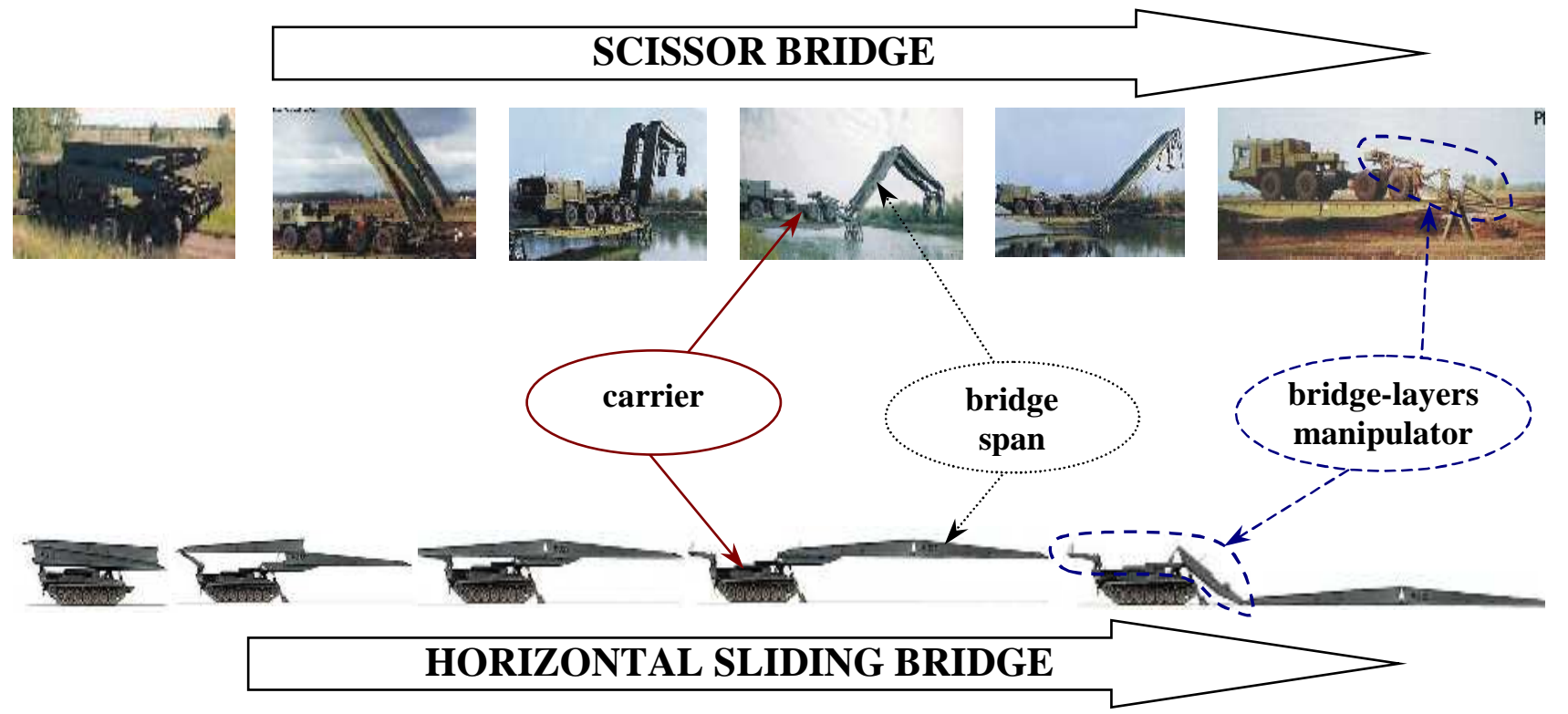

Fig. 1. Pattern of working cycle of bridge-layers manipulator

Growing requirements of lengths and widths of bridge span as well as theirs load capacity cause, that critical element of mechanized bridges are bridge-layers manipulators.

Authors assumed, that as results of development of bridges carriers ( base vehicles) are easily visible, but development of bridge-layers manipulators is strictly classified. There is lack of publication about this subject, and the methods of construction which results in new final solutions are knowhow of manufacturers. Fundamentally different character of pattern of working cycle and resulting from this specific of working load of bridge-layers manipulator elements in scissors and horizontal sliding bridges causes that analysis and identification of theirs structure should be conducted separately.

In paper authors will only concentrate on design of scissors bridges manipulators in particular in field of formation of theirs geometrical structures as well as implementation of existing methods to solution of this problem.
In the figure 2 was shown the developmental process of design of technical devices about multi-linked structure mechanisms (two and three-dimensional). According to authors at the beginning evolution of design processes was focused on limitation of intuitive solutions in process of design and replace it by utilization of scientific research for modernization of existing solutions. At present we deal with so called integrated design in which expert teams work on utilization of knowledge connected with mathematics and physics to resolve respective problems. In areas of this methodology its possible to identify three basic aspects: automation control, degree of freedom of structure, working load of structures elements. Mentioned factors result in solutions methods were taken. In whole system there was identified bridge-layers manipulators as two-dimensional mechanisms. In this way the area of research was limited to methods of design of structure of bridge-layers manipulators and there was identify the scope of this methods for formation of geometrical structure of manipulator. 
Analysis of literature, in field of formation of structure of technical devices $[1,6,7,8]$, making visible limited possibilities of utilization of existing methods to synthesis of bridge-layers manipulators structure. They not to take into account occurrence of different kinematic pairs in structure (simple and multiple) - in connection with specific conditions of bridge-layers manipulator working cycle. The goal of latest works concerning of creation of geometrical structures of technical devices connected with transfer of loads through elements of construction was only specification of general structure enable performance of assumed working cycle and kinematics of movement. transporting position) and weight limitation related bridge-layers manipulators elements;

- limitation related disposal forces in hydraulic cylinder resulting from mechanical properties of manipulators elements as well as proprieties of bridge carrier (mainly weight limitations of mechanized bridges);

- necessity of saving great stability in whole working area;

- possibility of occurrence of particular positions in manipulators working space.

Therefore, taking under consideration mentioned above conditions process of design new solution of bridge manipulator should be performed in this way that operators role in this systems ought to be only to supervise alternatively

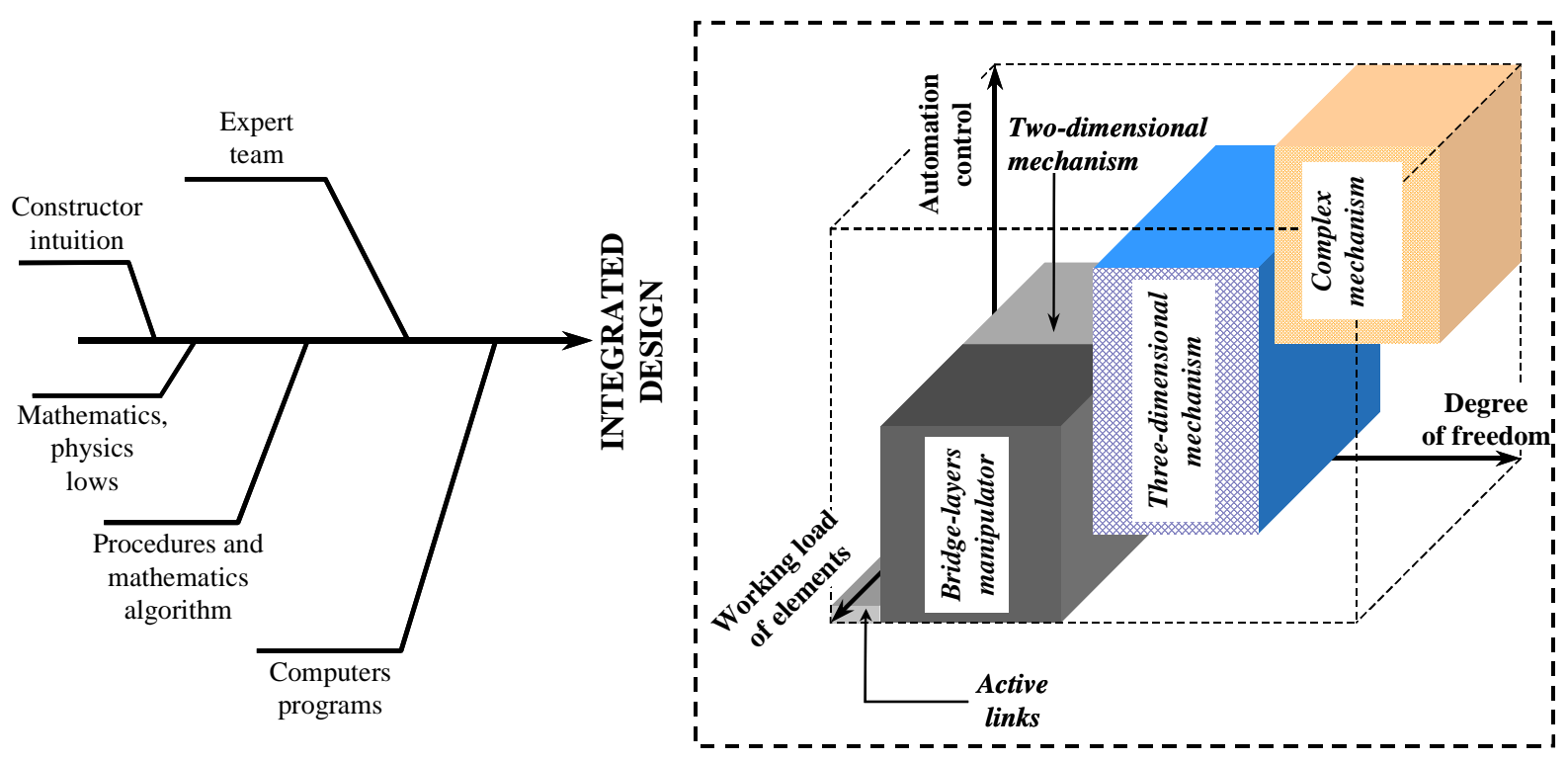

Fig. 2. Process of design of technical devices

Analysis of constructional solutions contemporary bridgelayers manipulators as well as carried out preliminary calculation concerning formation of bridge-layers manipulators structure showed that accessible - described in literature methods relate this area - not permit to generate whole data set of constructional solutions.

Fundamental role in design process of bridge manipulators plays analysis of character of working cycle and conditions its using as well as influence of mentioned above factors on degree of loads of respective elements.

Characteristics of working cycle of bridge-layers manipulators are as follows:

- occurrence of strongly changing determined loads (derived from bridge span) and random loads (from blast of air ) as well as incidental (mainly caused by icing and soiling of bridge span);

- forced character of working cycle power transmission system - change of straight-line motion of hydraulic cylinder to plane motion of bridge span;

- dimensions limitation (resulting from imposed space in to correct of automatic system. It is obvious, that choice of structure of created kinematics systems of bridge-layers manipulator should be conducted according to definite methodology. In further part of paper there will be showed approach to synthesis of structure of scissors bridge-layers manipulators on the base new mechanized bridge design in Poland - named MS-20.

\section{SYNTHESIS OF BRIDGE-LAYER MANIPULATOR STRUCTURE}

Fundamental role in process of design of new kinematics systems of technical devices has accomplishment of exact identification of elements of manipulators mechanism and assumption for them general structure. In bridge-layers manipulator there is possible to identify such elements of construction and their relationships which create base of this structure and take part in process of exploitation of this technical devices - by to stiff connection of working mechanisms or permit to execute motions necessary to performance of this process $[9,10]$. 
On the basis of analysis of existing solutions it was presumed that five-link bridge-layers manipulators will be subject analysis. Essential matter during process of defining collection of possible solutions of structures bridge-layers manipulator is identification of common features, characterizing these manipulators. This common features point simultaneously elements which should be included in every scissors bridge-layer manipulators (fig. 3). They are as follows:

- passing wheeled or caterpillar chassis (1) - passive link

- arm of bridge-layer manipulator fixed to main body of chassis (2);

- bridge span ( passive link) fixed by non- rotary motion on extension arm of bridge-layer manipulator (3);

- moving links (e.g. hydraulic cylinders), assuring rotary motion (moving) element of bridge-layers manipulator in relation to chassis (4).

\section{Bridge BLG-67 (Poland)}

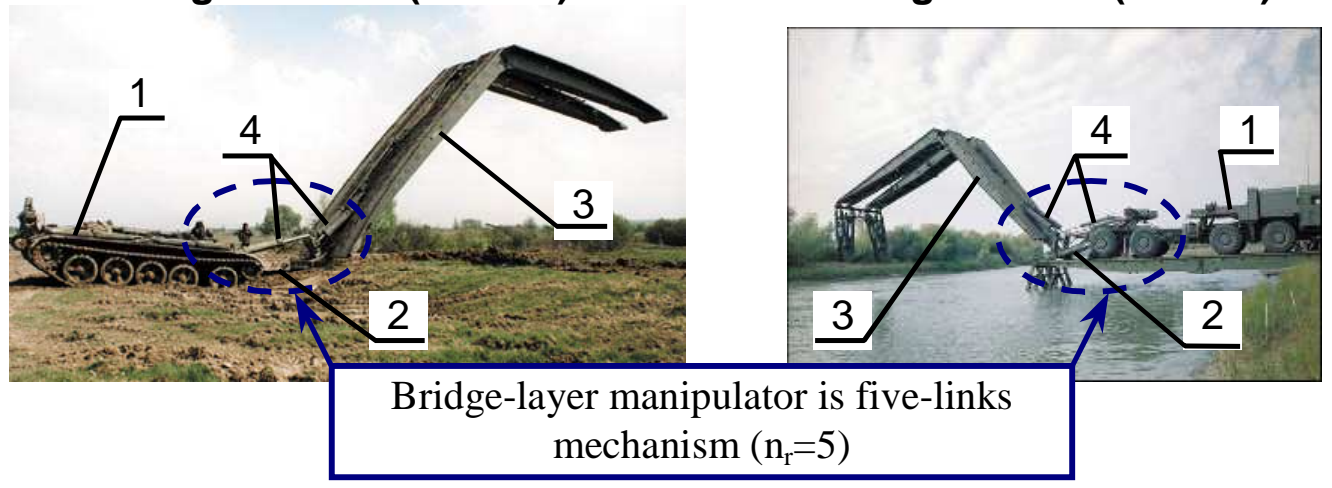

Fig. 3. Essential elements scissors bridge-layer manipulator (describtion in paper)
For further analysis the components were established for dependence (1):

$\mathrm{W}=0$ - in first stage it was presumed that there will be searched invariable system;

$\mathrm{W}_{\mathrm{C}}=0-$ in first stage it was presumed, that it is lack of moving links;

$\mathrm{W}_{\mathrm{B}}=3$ - results from mobility of passive links in plane system.

From mentioned above presumptions result value $\mathrm{W}_{\mathrm{L}}=-3$.

On the other hand assumed mobility of linking chain $\mathrm{W}_{\mathrm{L}}$ in bridge-layer manipulator may be expressed by meaning of movement of plane mechanism general equation:

$$
W_{L}=3 * n_{r}-1 * p_{4}-2 * p_{5}
$$

where: $n_{r}$ - number of moving links in structure of mechanism of bridge-layer manipulator; $\mathrm{p}_{4}, \mathrm{p}_{5}$ - of kinematics pairs IV and V class;

\section{Bridge TMM-6 (Russia)}

There were identified two methods of synthesis of this type of mechanisms:

- on basis of linking chain method,

- by utilization of integer programming.

\section{A. Structural synthesis of bridge-layer manipulator on the basis of linking chain method}

This method during process of formation takes into consideration kinematic objective function of solution, points different character of moving and passive links, moreover emphasizes existence of linking chains in transmission of movement between these two kinds of links $[1,7,8]$.

Starting point in this method is mobility created structure $\mathrm{W}$ (in meaning of number of degrees of freedom) expressed by dependence $[1,8]$ :

$$
W=W_{C}+W_{B}+W_{L}
$$

where: $\mathrm{W}_{\mathrm{C}}$ - elementary mobility delivered to structure by moving links; $\mathrm{W}_{\mathrm{B}}$ - disposal mobility of passive links ( before inclusion to structure); $\mathrm{W}_{\mathrm{L}}$ - resulting mobility of linking chain.
After taking into consideration of presumptions $\left(\mathrm{p}_{4}=0\right.$, $\left.\mathrm{W}_{\mathrm{L}}=-3\right)$ - we have:

$$
3 * n_{r}+3=2 * p_{5}
$$

from this equation for five-links systems $-\mathrm{n}_{\mathrm{r}}=5$ (which were presumed on basis of analysis of existing constructional solutions of scissors bridge-layer manipulator e.g. TMM-6, MTU-90), there were specified number of kinematics pairs $\mathrm{p}_{5}=9$.

Taking into account mentioned above presumptions there were specified system of equations which describe $n_{r}+1$ linkstructure closed kinematic chain:

$$
\left\{\begin{array}{c}
6=n_{2}+n_{3}+n_{4}+n_{5} \\
18=2 n_{2}+3 n_{3}+4 n_{4}+5 n_{5}
\end{array}\right.
$$

Solution of system of equations (4) in set of natural numbers, taking into consideration presumptions are showed in table 1. 
TABLE 1

SOLUTION OF SYSTEM OF EQUATIONS (4) FOR FIVE-LINKS' BRIDGE-LAYER MANIPULATORS

\begin{tabular}{|c|c|c|c|c|}
\hline \multirow{2}{*}{$\begin{array}{c}\text { Alternative } \\
\text { designs }\end{array}$} & \multicolumn{4}{|c|}{ Number of links } \\
\cline { 2 - 5 } & $\boldsymbol{n}_{\boldsymbol{2}}$ & $\boldsymbol{n}_{\mathbf{3}}$ & $\boldsymbol{n}_{\boldsymbol{4}}$ & $\boldsymbol{n}_{\boldsymbol{5}}$ \\
\hline $\boldsymbol{1}$ & 2 & 2 & 2 & 0 \\
\hline $\mathbf{2}$ & 2 & 3 & 0 & 1 \\
\hline $\mathbf{3}$ & 3 & 1 & 1 & 1 \\
\hline $\boldsymbol{4}$ & 3 & 0 & 3 & 0 \\
\hline $\mathbf{5}$ & 4 & 0 & 0 & 2 \\
\hline
\end{tabular}

In the next stage, there is created way of connection of links into kinematic pairs, so there should be recorded matrix form. Every line and every column of matrix of connections is subordinated to definite links and point number and kind of connections, which respective link creates with others links of system. Showing recorded structure in form of system of equations (after earlier consideration of creation conditions of matrix of connections) we can make solutions of this equation in set of natural numbers and we are given matrix of connections.

On fig. 4 it is showed examples of structure of linking chain (bridge-layer manipulator).
Variant 1

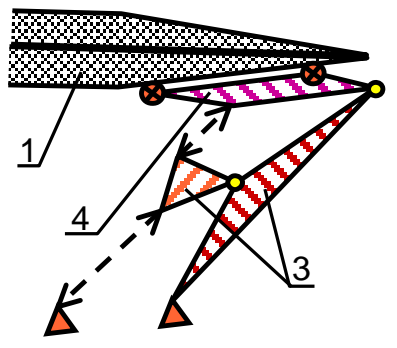

Variant 3

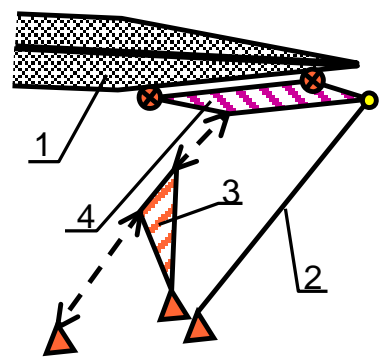

Variant 5

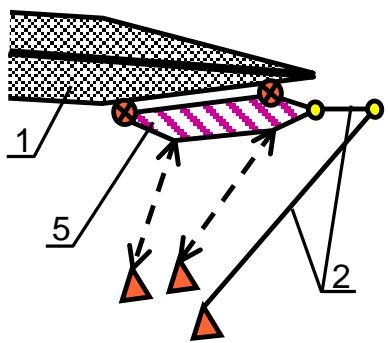

$\triangle$ points of fixing

of manipulator to carrier

$\oplus$ points of fixing bridges span

to manipulator

o kinematic pairs joined rotary

$\leftarrow \rightarrow$ hydraulic cylinder
Fig. 4. Example of graphic form of linking chain's structure for five-links bridge-layer manipulator:

1 - bridge span, 2 - two-joint links, 3 - three-joint links, 4 - four-joint links, 5 - five-joint links
Obtained structures of bridge-layer manipulator on the basis of linking chain method lack solutions consisted of smaller number of links. To resolve this problem integer programming was applied.

B. Structural synthesis of bridge-layer manipulator by utilization of integer programming

Integer programming method allows to specify structure of bridge-layer manipulator $\mathrm{x}^{\mathrm{o}}\left(\mathrm{n}_{2}, \mathrm{n}_{3}, \mathrm{n}_{4}, \mathrm{n}_{5}\right)$ - composed of links with given nodal, and accomplished:

- objective function:

$$
6-\left(n_{2}+n_{3}+n_{4}+n_{5}\right) \rightarrow \max
$$

- boundary conditions:

$$
\begin{aligned}
& 2 n_{2}+3 n_{3}+4 n_{4}+5 n_{5} \leq 18 \\
& 2 n_{2}+3 n_{3}+4 n_{4}+5 n_{5} \geq 12
\end{aligned}
$$

$n_{2} \geq 2 ; n_{i} \geq 0 ; n_{i}$ - integer for $\mathrm{i}=2,3,4,5$

Solution of equation (5) under conditions (6) by meaning of method of division and estimation is showed on fig. 5, whereas the most precious (structurally simple) solutions from gained set of structures of bridge-layer manipulator is showed on fig. 6.

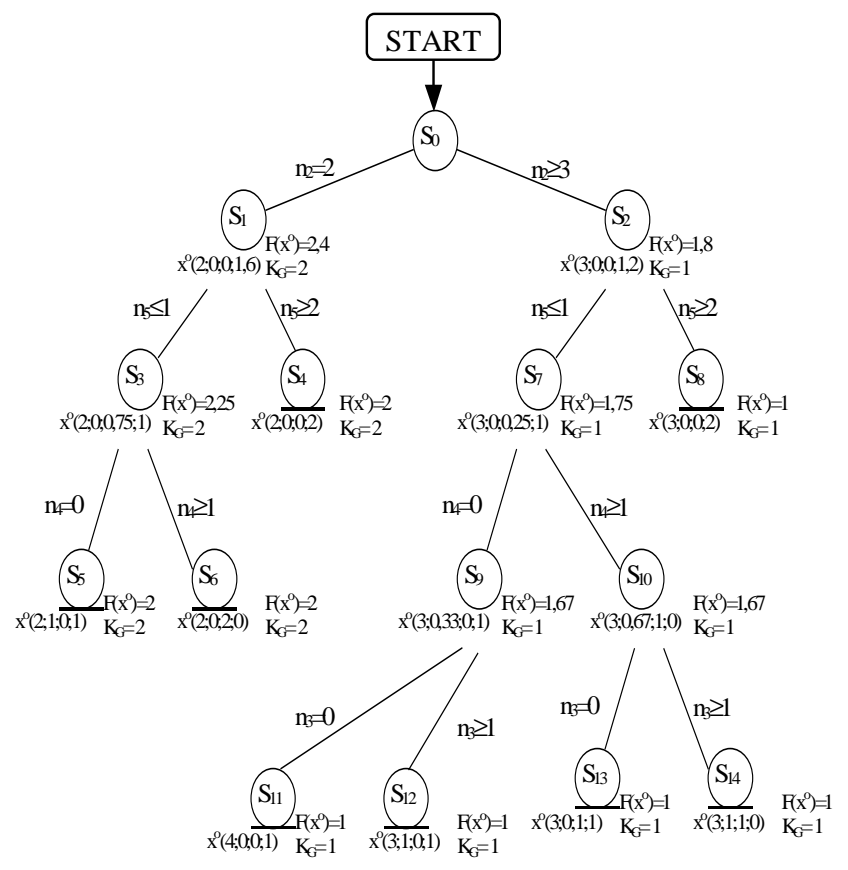

Fig.5. Solution of equation (5) on base of method of division and estimations concurrently with specification of geometrical structure of closed chain $\mathrm{x}^{\mathrm{O}}\left(\mathrm{n}_{2}, \mathrm{n}_{3}, \mathrm{n}_{4}, \mathrm{n}_{5}\right)$ 
a)

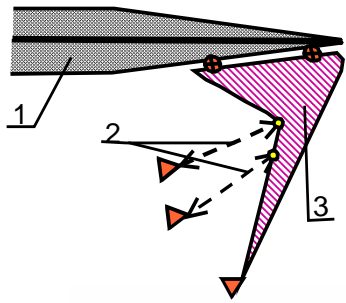

b)

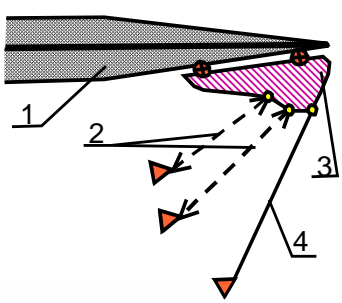

c)

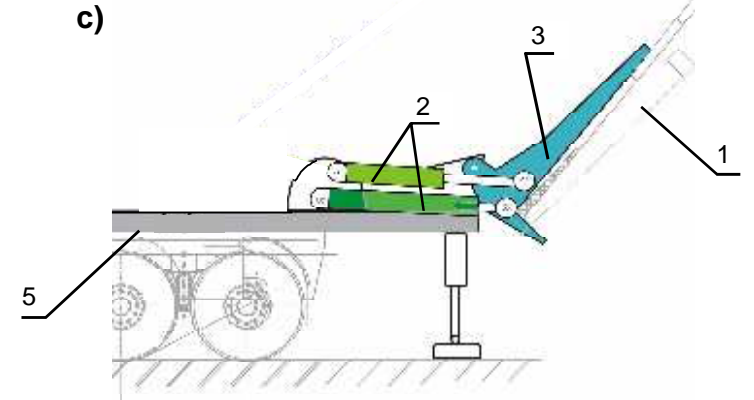

Fig. 6. Example of graphic form of structures of bridge-layer manipulator gained by utilization of integer programming: a) manipulator with one-piece lever, b) manipulator with two-part broken lever, c) scheme of constructional of manipulator for bridge MS-20 (in accordance with variant a)

1 - bridge span, 2 - hydraulic cylinder, 3 - manipulators lever, 4 - two-joint links, 5 - semi-trailer

\section{CONCLUSION}

In this paper there was proposed approach to creation of geometrical structure of bridge-layer manipulator. Showed method of synthesis of geometrical structure of manipulator enable to specify the set of structure from which the simplest may be implemented in practice. There was point the meaning of analysis of contemporary solutions because it permit proper preparation of presumptions. Moreover this analysis have great influence on respective steps of process of creation of new structure. Utilization of methods of structural synthesis and optimization should accelerate the process of searching reasonable (simplest) structures and selection of geometrical parameters of bridge-layer manipulator. It is necessary to take into consideration development of automation control working systems these technical devices - because of possibility of occurrence of particular positions in some links.A conclusion section is required. Although a conclusion may review the main points of the paper, do not replicate the abstract as the conclusion. A conclusion might elaborate on the importance of the work or suggest applications and extensions.

\section{REFERENCES}

[1] E. Adamczyk, Type and geometrical synthesis of multilink loadcarrying structures of working machines. Prace naukowe Instytutu Konstrukcji i Eksploatacji Maszyn Politechniki Wrocławskiej nr 71, Copyright by Politechnika Wrocławska, Wrocław 1992.
[2] E. Budny, Rational design basis of multisegmental working attachment of construction machines on example of a backhoe hydraulic excavators. Prace naukowe Mechanika z. 148, Copyright by Politechnika Warszawska, Warszawa 1993.

[3] C.F. Foss, T.J. Gander, Jane's military vehicles and logistic. Twentieth edition 1999-2000, Jene's Information Group Limited, Surrey 1999.

[4] R.S. Garfikel, G. L. Nemhauser, Integer programming, John Wiley \& Sons, New York-London-Sydney-Toronto 1972.

[5] E. Ignasiak i inni, Badania operacyjne. PWE, Warszawa 1996.

[6] S. Miller, Układy kinematyczne. Podstawy projektowania. WNT, Warszawa 1988.

[7] S. Miller „Podstawy syntezy strukturalnej układów kinematycznych”, WNT, Warszawa - Wrocław 1984.

[8] T. Młynarski, A. Listwan, E. Pazderski, Teoria maszyn i mechanizmów. Synteza i analiza strukturalna mechanizmów, Copyright by Politechnika Krakowska, Kraków 1997.

[9] A. Morecki, J. Oderfeld, Podstawy mechanicznej teorii maszyn. PWN, Warszawa 1986.

[10] A. Olędzki, Podstawy teorii maszyn i mechanizmów. WNT, Warszawa 1987.

[11] G. Pahl, W. Beitz, Konstruktionslehre. Handbuch für Studium und Praxis. Copyright by Springer-Verlag, Berlin-Heidelberg 1977.

[12] STANAG 2021 - ENGR Military computation of bridge ferry raft and vehicle classifications. 